\title{
Pendekatan Joyful Learning dalam Pembelajaran Microteaching di Era Revolusi Industri 4.0
}

\author{
Sri Handayani, Riyani, Khala Kirana \\ Slamet Riyadi University \\ handayn95@gmail.com
}

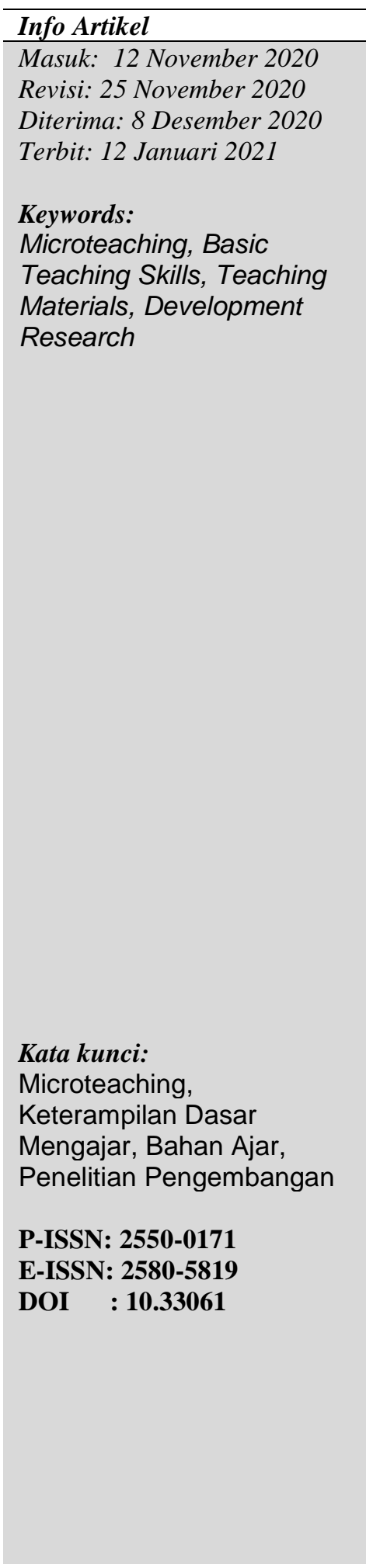

\begin{abstract}
This study aims to: (1) identify the implementation of Microteaching learning, (2) need analysis for Microteaching teaching materials that are in accordance with the industrial revolution era 4.0, and (2) identify the advantages and disadvantages of Microteaching teaching materials.

This research is a development research with the ADDIE model. This research will be divided into three stages, namely in the first stage, this research will focus on analyzing the problem of microteaching learning. the second stage is to analyze the advantages and disadvantages of micro learning and the third stage is to develop teaching materials in the form of a proto-type microteaching module. The data in this study will be obtained through focus group discussions, observations, interviews and questionnaires. While the data obtained will be analyzed using qualatative data analysis techniques Miles and Huberman which consists of data display (data display), data reduction and verification.

The results showed that carried out in the even semester of the 2019/2020 academic year Microteaching learning experienced problems due to the COVID-19 pandemic at the end of February. So that microteaching learning cannot be fully implemented according to the semester learning plan, microteaching learning cannot be carried out in the microteaching laboratory room but is carried out online at the location of each student ... of course this makes it difficult for students because it is different from the initial concept of theory where students can practice theory of basic skills teaching with classmates (peerteaching) and supervised by practitioners, lecturers and also getting input from peers. To overcome this problem, it is necessary to have the creativity of lecturers who teach courses to adjust to the conditions that are being experienced during the pandemic. The lecturers then use a joyful learning strategy in Micrteaching learning. Before students do their teaching practice, the lecturer equips students with virtual joyful learning theory so that students can practice in pleasant psychological conditions but still achieve the predetermined learning outcomes.
\end{abstract}

\begin{tabular}{l} 
Abstrak \\
\hline Penelitian ini bertujuan untuk : (1) mengidentifikasi pelaksanaan \\
pembelajaran Microteaching, (2) keperluan ( need analysis) untuk bahan \\
ajar pengajaran Microteaching yang sesuai dengan era revolusi indutri 4.0, \\
dan (2) mengidentifikasi kelebihan dan kekurangan bahan ajar \\
Microteaching. \\
Penelitian ini merupakan penelitian pegembangan dengan model ADDIE. \\
penelitian ini akan dibagi menjadi tiga tahap, yaitu pada tahap pertama, \\
penelitian iniakan berfokus pada anlisis masalah tentang pembelajaran \\
microteaching. tahap kedua adalah menganalisis kelebihan dan \\
kekurangan pembelajaran mikro dan tahap tiga adalah mengembangkan \\
bahan ajar berupa proto tipe modul microteaching. Data dalam penelitian \\
ini akan diperoleh melalui focus group discussion, observasi,wawancara \\
dan questionaer. Sedangkan data yang diperoleh akan dianalisis dengan \\
menggunakan teknin analisis data qualatative Miles and Huberman yang \\
terdiri dari sajian data (data display), reduksi data dan verifikasi. \\
Hasil penelitian menunjukan yang dilaksanakan pada semester genap \\
tahun akademik 2019/2020 pembelajaran Microteaching mengalami
\end{tabular}


permasalahan dikarenakan adanya pandemi covid 19 pada akhir Febuari. Sehingga pembelajaran microteaching tidak dapat sepenuhnya dilaksanakan sesuai dengan rencana pembelajaran semester, pembelajaran microteaching tidak dapat dilaksanakan di ruang laboratorium microteaching akan tetapi dilaksanakan secara daring di lokasi masingmasing mahasiswa..tentu hal ini menyulitkan mahasiswa karena berbeda dengan konsep awal teori dimana mahasiswa dapat mempraktekan teori keterampilan dasar mengajar dengan teman satu kelas ( peerteaching) dan disupervisi oleh praktisi, dosen dan juga mendapatkan masukan dari teman sejawat. Untuk mengatasi permasalahan tersebut diperlukan kreatifitas dosen pengampu mata kuliah untuk menyesuaikan kondisi yang sedang dialami dalam masa pandemi. Dosen pengampu selanjutnya menggunakan strategy joyful learning dalam pembelajaran Micrteaching. Sebelum mahsiswa melakukan praktek mengajar, dosen membekali mahsiswa dengan toeri joyful learning secara virtual sehingga mahsiswa dapat melakukan praktek dengan kondisi psikologis yang menyenangkan namun tetap mencapai learning outcome yang telah ditentukan.

\section{PENDAHULUAN}

Era Revolusi Industri menuntut perkembangan dan perubahan di berbagai bidang, termasuk bidang pendidikan sebagai sumbu perkembangan nasional. Salah satu unsur yang kuat di bidang pendidikan adalah kualitas Sumber daya Manusia,dalam hal ini guru atau tenaga pendidik. Begitu pula dengan guru bahasa Inggris. Materi yang disampaikan merupakan hal yang penting dalam perkembangan jaman karena bahasa Inggris merupakan bahasa international. Selain bahasa internasional juga merupakan bahasa formal. Sehinga pembelajaran bahasa Inggris diperlukan guru yang profesional yang mampu mengajarkan bahasa Inggris kepada siswa SMP maupun SMU.

Perguruan tinggi, terutama LPTK sebagai penghasil guru mempunyai peranan yang penting dalam mencetak guru yang berkualitass dan profesional. Salah satu mata kuliah yang membekali mahasiswa untuk terampil mengajar adalah pembelajarn Mikro merupakan mata kuliah praktek yang diberikan pada mahasiswa semester VI sebagai bekal kompetensi utama dalam keterampilan mengajar. Pembelajaran mikro yang mendasari sistem pembelajaran peer teaching akan diwarnai dengan berbagai perkembangan jaman, khususnya pada era disrupsi ini,guru diwajibkan untuk mempunyai kemampuan yang serba digital dan tetap menjaga literasi insani serta kemuthakiran data.

Berdasarkan prelimenary research yang dilakukan pada 11 Maret 2020, pada mata kuliah semseter VI Prodi PBI FKIP Unisri, ditemukan permasalahan padapembelajaran Mikro sebagai berikut: (1)berasal dari Dosen, sarana prasarana maupun dari proses pembelajaran. Dari sisi dosen, dosen mempunyai masalah dalam penggunaan media yang menunjang pembelajaran berbasis digital karena sarana media nya masih konvensional. Dosen juga masih menemui kesulitan dalam mengadakan kerjasama untuk menghadirkan praktisi dalam mata kuliah Microteaching. Sedangkan pada sisi sarana prasarana, laboratorium microteaching masih terbatas baik kuantitas maupun kualitasnya. Dalam proses pembelajaran, mahasiswa praktikan masih menemui kesulitan dalam mempraktekan beberapa keterampilan dasar mengajar yang menuntut kemampuan serat keterampilan analsis tinggi, yaitu keterampilan stimulus variation, giving explanation and giving illustration 
Penelitian ini merupakan penelitian pengembangan dengan model ADDIE, Penelitian Pengembangan atau Research and Development (R\&D) Menurut Gay (1990) merupakan suatu usaha atau kegiatan untuk mengembangkan suatu produk yang efektif untuk digunakan sekolah, dan bukan untuk menguji teori. Sedangkan Borg and Gall (1983:772) mendefinisikan penelitian pengembangan sebagai berikut: "Educational Research and development ( $R$ \& $D$ ) is a process used to develop and validate educational products. The steps of this process are usually referred to as the $R \& D$ cycle, which consists of studying research findings pertinent to the product to be developed, developing the products based on these findings, field testing it in the setting where it will be used eventually, and revising it to correct the deficiencies found in the filed-testing stage. In more rigorous programs of R\&D, this cycle is repeated until the field-test data indicate that the product meets its behaviorally defined objectives. Penelitian ini dilakukan mulai 25 Februari 2020 samapai dengan 25 Februari 2021 di Fakultas Keguruan dan IImu Pendidikan Universitas Slamet Riyadi Surakarta. Adapun langkah-lagkah dalam penelitian $R$ and $D$ adala (a).Analisis kebutuhan,- Pada analisis kebutuhan ini, peneliti akan mencariinformasi tentang pelkasanaan pengajaran microteaching di fkip unisri untuk mengidentifkasi masalah dan kebuthan mata kuliah microteaching; (b) b. Studi literatur,- pada tahap ini, peneliti akan mecari refrensi dan data empiris di lapangan tentang pembelajaran microteaching di fkip unisri, (b) Riset skala kecil,-riset kecil ini dilakukan untuk mengetahui kelebihan dan kekuranan atas hasil identifikasi masalah serta studi Iteratur, (d) Perencanaan Penelitian (Planning) Perencanaan dalam penelitian R\&D meliputi: merumuskan tujuan penelitian, memperkirakan hal-hal yang dibutuhkan dalam penelitian, merumuskan kualifikasi peneliti dan bentuk partisipasinya dalam penelitian; dan ( e) Pengembangan Desain (Develop Preliminary of Product)Tahapan ini meliputi: 1) Membuat desain produk yang akan dikembangkan, 2) Menentikan sarana dan prasarana yang dibutuhkan selama penelitian, 3 )Menentukan tahap-tahap pengujian desain di lapangan. Sumber data dalam. penelitian ini adalah: (1) sumber data primer, yaitu peristiwa pembelajaran mikro serta modul pembelajaran micro, dan ( 2) data premier, yaitu referensi dan penelitian terdahulu tentang pembelajaran mikro. Data dalam penelitian ini diperoleh dengan menggunakan tiga teknik, yaitu obserrvasi, wawancara dan focus group discussion. Observasi akan dilakukan dengan mengamati proses pembelajara microteaching. Wawancara akan dilakukan dengan mahasiswa dan dosen pengampu mata kuliah microteaching di fakultas keguruan dan ilmu pendidikan unisri. Sedangkan FGD akan dilakukan dengan dosen pengampu mata kuliah microteaching untuk membahas insrtument dan prototipe penelitian. Data yang telah diperolah kemudain akan dianalisis dengan menggunakan teknik analisis kualitatif interaktif Miles and Huberman

\section{PEMBAHASAN}

\section{Hasil Yang Dicapai}

Penelitian ini merupakan penelitian pengembangan yang akan dilakukan selama dua tahap dalam kurun waktu dua tahun. Pada tahun pertama ini dilakukan identifikasi masalah dan analisis kebutuhan serta kelebihan dan kekurangan yang berhubungan dengan bahan ajar mata kuliah Microteaching. Bedasarkan hasil pemerolehan data melalui wawancara dan diskusi terbatas antara tim dosen pengampu mata kuiah Microteaching di PBI Unisri dan salah satu dosen pengampu mata kulia di Prodi PGSD, dapat ditemukan bahwa bahan ajar yang diberikan padamata kuliah Microtecahing berupa buku ajar dan handout yang berisi tentang keterampilan dasar mengajar dan perangkat pembelajaran. 
Akan tetapi pada semster genap tahun akademik 2019/2020 pembelajaran Microteaching mengalami permasalahan dikarenakan adanya pandemi covid 19 pada akhir Febuari. Sehingga pembelajaran microteaching tidak dapat sepenuhnya dilaksanakan sesuai dengan rencana pembelajaran semester, pembelajaran microteaching tidak dapat dilaksanakan di ruang laboratorium microteaching akan tetapi dilaksanakan secara daring di lokasi masing-masing mahasiswa..tentu hal ini mneyluitkan mahasiswa karena berneda dengan konsep awal teori dimana mahasiswa dapat mempraktekan teori keterampilan dasar mengajar dengan teman sartu elas ( peerteaching) dan disupervisi oleh praktisi , dosen dan juga mendapatkan masukan dari teman sejawat. Untuk mengatasipermsalahan tersebut diperlukan kreatifitas dosen pengampu mata kuliah untuk menyesuaikan kondisi yang sedang dialami dalam masa pandemi. Dosen pengampu selanjutnya menggunakan strategi joyful learning dalam pembelajaran Micrteaching. Sebelum mahsiswa melakukan praktek mengajar, dosen membekali mahsiswa dengan toeri joyful learning secara virtual sehingga mahsiswa dapat melakukan praktek dengan kondisi psikologis yang menyenangkan namun tetap mencapai learning outcome yang telah ditentukan.

Dalam penelitian ini, peneliti ini, peneliti mengali serta mengambarkan fenmena pembelajaran praktek mengajar microteaching dengan pendekatan joyful learning. dan berikut hasil penelitian yang dilkaukan di lapangan selma masa pandemi covid 19 dalam mata kuliah microtecahing.

a. Deskripsi data pembelajaran Microteaching di PBI FKIP Unisri

Microteaching merupakan mata kuliah wajib yang mempunyai bobot 3 sks. Mata kuliah Micro Teaching merupakan salah satu mata kuliah wajib bagi mahasiswa program studi PBI dan sebagai syarat Magang. Micro Teaching adalah mata kuliah yang harus dilatihkan dalam kelas secara sederhana, beberapa kali agar mahasiswa terampil mengajar dalam kelompok kecil, diharapkan bila telah dianggap layak (standar), pada pembelajaran pada kelas besar dapat teratasi. Ketrampilan dan sikap sesuai dengan kompetensi guru yang telah di tentukan dalam Permindiknas No 16 tahun 2007. Dalam pengajaran kompetensi dapat di aplikasikan dalam real teaching. Sehingga mahasiswa dapat memiliki empat kompetensi yang disyaratkan bagi guru bisa dicapai yaitu kompetensi Paedagie kompetensi professional, kompetensi kepribadian dan kompetensi sosial. Mata kuliah ini mempunyai capaian pembelajaran mata kuliah Menjelaskan proses belajar mengajar/real teaching, Memahami konsep, tujuan dan tahap dalam pembelajaran microteaching, Menjelaskan contoh-contoh metode pengajaran bahasa Inggris berbasis era revolusi industri 4.0, Memahami konsep keterampilan dasar mengajar berbasis era revolusi industri 4.0, Merancang RPP dalam lingkup kecil/mikro berbasis era revolusi industri 4.0 dan Terampil melaksanakan pembelajaran mikro berbasis era revolusi industri 4.0. Berhubung di era pandemi ini mahasiswa tidak dapat melakukan praktek mengajar, maka mereka melakssanakan praktek di tempat masing-masing dan merekamnya dalam bentuk video.

b. Deskripsi Data praktek pembelajaran Microteaching oleh mahasiswa di era pandemi dengan Strategi Joyful Learning 
Pada praktek microteaching dengan menggunakan strategi joyfullearning, mahasiswa mempraltekan keterampilan dssar mengajar sesuai dengan petunjuk dan bekal materi yang diarahkan oleh dosen, yaitu:

a) Mahasiswa microteaching kelas mensetting kelas mereka di rumah yang dapat menarik perhatian siswa

Dalam praktek mengajar, mahassiwa membuat kreasi kelas di lokasi masingmassing agar tercipta suasana pembelajarn formal dan menyenangkan. Dari 38 mahasisw a, 6 mahassiwa mendesign kelas yang mereka pinjam dari kampus, 11 mahassiwa mendesign kelas di ruangn tamu di dalam rumah, 13 anak melakukan praktek di luar rungan dan 8 anak melakukan praktek di beranda kos. Masingmassing mahasiswamendesign ruangan kelas mereka semenarik mungkin pada kelas indoor, mahasiswa menghiasi ruangan dengan ornamen yang sesuai degan topik mereka. Berikut deskripsi rinci rungan kelas yang digunakan dalam praktek microteaching.

Pada mahasiwa yang menggunakan ruang tamu sebagai ruang kelass microteaching, mereka mendesign ruang tamu mereka seperrti layaknya ruang kelas selain menseeting kursi untuk dapat diduduki berhadapan. Mereka juga menambahkan white board kecil maupu peralatan lainya yang dapat digunakan untuk menulis. Kelas juga variatif debgan tulisan dan ornamen yang berhubngan dengan topik pembelajaran bahasa Inggris maupun slogan-slogan dalam bahasa Inggirs maupun bahasa Indonesia.

Pada kelas indoor mahassiwa menggunakan taman rumah sebagai kelas, beberapa mahasiswa menggunakan taman dengan dilengkapikursi dan papan tulis untuk melakukan praltek mengajar. Mereka merasa nyaman dan relax dalam melakukan aktivitas pembelajaran microteaching. Dengan demikian mereka merasa mdah dan tidak terrbebani dalam melkaukan praktek keterampilan dasar mengajar. Enam mahssiwa yang menggunakan ruang di kampus mendesign kelasnya dengan memanfaatkan jaringan internet dengan praktek mengajar menggunakan platform zoom meeting untuk mengajar teman sebaya sehingga ruang kelas dipastikan mempunyai jaringan yang kuat untuk kelancaran penyampaian materi. Sedagkan mahssiwa yang menggunakan fasilitaskos dengan memanfaatkan beranda kos, ruang santai dan ruang tamu, mereka mengajar teman kos sesama mahasasiswa baik teman satu prodi maupun prodi yang berbeda.

b) Mahassiwa memberikan perhatian khusus kepadavmateri pembelajaran yang dapat digunakan di kelas

Agar materi yang disampaikan dalam praktek Microteaching menarik untuk dibawakan dan mudah diserap oleh peserta didik, maka praktikan diarahkanuntuk melakukan hal yang kreatif terhadap mareri ajar.praktikan diminta untuk membuat video pembelajaran singkat tentang materi ajar, video ini diharapkan dapat merangsang sensorik baik audio maupun visual sehingga dapat lebih menarik perrhatian dan merangsang respon positif dari peserta didik. Dari 38 mahasiswa praktikan yang membuat variasi materi ajar, 10 praktikan membuat video pembelajaran singkat,8 praktikan membuat voice message dan 20 mahasswa praktikan membuat ilustrasi berupa gambar dan chart untuk materi ajarnya. 
c) Mahasiswa membuat pengalaman pembelajaran relevan terrhadap hal yang menarik bagi peserta didiknya

Praktikan di era sekarang merupakan generasi milenial sehingga bijaksana bagi dosen pengampu mata kuliah microteaching untuk mengatrkan mahasiwa praktikan untuk praltek mengajar denngan menerapkan pengetahuan sertaketerampilan dasar mengajar pada`masa digital.baik praktikan maupun peserta didik mempunyai ketertarikan yag besar terhadap hal-hal yang berhubungan dengan carakerja mesin maupun aplikassi-aplikassi menarik lainnya.padapraltel mengajar di erapandemi ini, praktikan mengajar peserta didik untuk membuat vlog dalam mengasah keterapilan speaking skill. Sendangkan untuk kreatifitas menulis, praktikan mengajak peserta didik untuk menulis pesan lewat platform google classroom dan whatshap group dengan menggunakan bahasa Inggris. Peserta didik maupun praktikan merasa nyaman dan senang belajar bahasa Inggris karena mereka merasa dekat dengan kehidupan dunia nyata yang mereka alami sehari-hari.

d) Mahasiswa menambahkan kejutan dan kebaharuan dalam pembelajaran .

Pada praktek microteaching, praktikan melaksanakan pembelajarn secara menarik dan kreatif dan bahkan memberri konsep baik media, materi maupun hal lain yang kreatif, inovatif dan mengejutkan peserrta didik. Dalam praktek ini dilakukan dengan berrbagai cara, yaitu praktikan mengenakan srempang dari kertas karton bertuliskan "We Love and Learn Engish", ada praktikan yang memberikan hal yang baru dan menarik bagi peserta didik. Salah satu siswa mengunakan bungkus chocholate yang menarik dan menceritakan sejarah, manfaat dan cara pembuatan chocolate. Hal ini sangat surprising parapeserrta didik.

\section{Pembahasan}

Dari hasil penelitian yang telah ditemukan berupa diskripsi pembelajaran microteaching selama pandemi dengan menggunakan pendekatan joyful learning, maka dapat dikatakan bahwa pembelajaran yang bermakna dapat dilakukan dengan menyesuaikan dengan kondisi serta situasi yang sedang dialami oleh peserta didik. Seorang educator dapat menentukan design pembelajaran dengan terlebih dahulu melakukan analisis situasi pada peserta didik. Dalam konteks penelitian ini , pada awalnya peneliti akan melakukan penelitian di laboratorium Microteaching di Fakuktas Keguruan dan IImu Pendiidikan. Namun dengan adanya situasi yang ada, akhirnya tim peneliti memutuskan untuk melakukan penelitian sesuai dengan kondisi serta situasi pandemi yaitu pembelajaran yang dilakukan secara daring. Karena microteaching merupakan mata kuliah praktek, maka agak kesulitan baik bagi dosen maupun mahasiswa praktikan. Untuk itu diperlukan pendekatan yang dapat membantu capaian pembelajaran mahasiswa. Hal ini sesuai dengan hasil penelitian berjudul The Implementation of Joyful learning Approach in Providing Learning Motivation for Elementary Students. Berdasarkan hasil wawancara dengan mahasiswa tentang pelaksanaan pembelajaran Microteaching secara daring, dapat ditemukan bahwa mahasiswa mempunyai persepsi terhadap pelaksanaan pembelajaran secara daring, menurut mereka ada kelebihan dan ada kekuranganya. Menurut mereka kelebihan yang dirasakan oleh mahasiswa dalam menempuh mata kuliah microteaching secaradaring adalah mereka dapat melaksanakan praktek secara mandiri dan otonom namun tetap menyenangkan karena dosenya menerapkan pendekatan joyful learning. 
Mahasiswa secara juga merasaterbantu dengan kesiapan secarapsikologis karena mereka tidak terbebani untuk mengajar di depan teman -teman sebaya mereka

\section{KESIMPULAN}

Dari hasil penelitian dapat disimpulkan bahwa pembelajaran microteaching di era pembelajaran microteaching sudah berjalan dengan memanfaatkan laboratorium Microteaching berbasis IT sehingga para mahasiswa dan dosen sudah dapat menggnakan peralatan berbasis IT pada laboratorium di Fakultas Keguruan dan IImu Pendidikan Universitas Slamet Riyadi Surakarta. Pada pelaksanaanya, pembelajaran Microteaching disesuaikan dengan situasi pandemi yang sedang dialami dengan situasi pandemi Covid 19 maka pembebelajaran dilakukan secara online. Berhubung di era pandemi ini mahasiswa tidak dapat melakukan praktek mengajar, maka mereka melakssanakan praktek di tempat masing-masing dan merekamnya dalam bentuk video. Untuk membantu mengatasi situasiini, dosen pengamu kemudian menerakan Joyful Learning dalam pembelajaran Microteaching. Mahasiswa microteaching kelas mensetting kelas mereka di rumah yang dapat menarik perhatian siswa ; Mahassiwa memberikan perhatian khusus kepadamateri pembelajaran yang dapat digunakan di kelas; Mahasiswa membuat pengalaman pembelajaran relevan terrhadap hal yag menarik bagi peserta didiknya ; dan Mahasiswa menambahkan kejutan dan kebaharuan dalam pembelajaran

\section{DAFTAR PUSTAKA}

Allen D, dan K. Ryan. 1969. Micro Teaching, Reading. Addison Wiesley Publishing Compo Inc, Mass.

Brown, G.1975. Micro-Teaching: a Programme of Teaching Skill. London: Methuen \& Co. Ltd.

Eggen, Paul dan Kauchak, Don. (2012). Strategi dan Model Pembelajaran. Jakarta:Indeks.

Gagne, M. Robert, Briggs, J. Leslie, dan Wager, W.Walter. (1992). Principles of Instructional Design. America: Harcourt Brace Jovanovich CollegePublishers.

Ibrahim, Sutini. (2011). Belajar, Pengajaran dan Pembelajaran (KonsepdanImplementasi). Pontianak: Fahruna Bahagia Press.

M. Djauhar Siddiq, dkk (2008). Pengembangan Bahan Ajar. Direktorat Jenderal Pendidikan Tinggi DEPDIKNAS.

Pribadi, Benny. A, (2009). Model Desain Sistem Pembelajaran. Jakarta: Dian Rakyat.

PP No. 16 Tahun 2007 Tentang Standard Kualifikasi Akademik Dan Kompetensi Guru.

Rustiyah, NK. 1982. Masalah-masalah Keguruan. Jakarta: Bina Aksara.

Sri Handayani.2018. Microteaching Practices based on Multiple Intelligence: A Research and Development of Students' Handbook for English Language Education.The 2nd International Conference on Education, Technology and Social Sciences 
Sri Handayani.2015. Peningkatan Fluency in Questioning Ketrampilan dasarMengajar Dengan Menggunakan Realia. Volume 10,Nomor 1 February 2015. Widya Wacana.

Sri Handayani. 2016. Pembelajaran Mikro Berdasarkan Pendekatan Konstruktivisme.Widya Wacana Vol 2 Sardiman. (2011). Interaksi dan Motivasi Belajar Mengajar. Jakarta: Rajawali Pers.

UU No. 14 Tahun 2005 Tentang Guru dan Dosen. 